\title{
Indices of Free Radical Oxidation in the Oral Fluid as Markers of Athletes' Funetional State
}

DOI: $10.17691 / \mathrm{stm} 2017.9 .3 .11$

Received November 24, 2016

K.N. Kontorshchikova, DSc, Professor, Head of the Department of Clinical Laboratory Diagnosis,

Faculty of Doctors'Advanced Training'; Professor, Department of Molecular Biology and Immunology,

Institute of Biology and Biomedicine';

Y.R. Tikhomirova, PhD, Associate Professor, Department of Clinical Laboratory Diagnosis,

Faculty of Doctors' Advanced Training';

A.N. Oychinnikov, PhD Student, Department of Biology and Physiology, Institute of Biology and Biomedicine2;

T.1. Kolegova, Student, Department of Molecular Biology and Biomedicine, Institute of Biology and Biomedicine2;

N.N. Churkina, Physician, Clinicodiagnostic Laboratory3;

S.Y. Kuznetsova, Physician, Clinicodiagnostic Laboratory3;

V.N. Krylov, DSc, Professor, Department of Biochemistry and Physiology, Institute of Biology and Biomedicine ${ }^{2}$

${ }^{1}$ Nizhny Novgorod State Medical Academy, 10/1 Minin and Pozharsky Square, Nizhny Novgorod, 603005,

Russian Federation;

'Lobachevsky State University of Nizhni Novgorod, 23 Prospekt Gagarina, Nizhny Novgorod, 603950,

Russian Federation;

${ }^{3}$ Privolzhsky District Medical Center of the Federal Medico-Biological Agency of Russia,

2 Nizhne-Volzhskaya naberezhnaya, Nizhny Novgorod, 603005, Russian Federation

The aim of the investigation was to study the efficiency of determining indices of free radical and peroxide processes in the oral fluid in highly qualified athletes under anaerobic interval exercise for the assessment of their functional state.

Materials and Methods. 23 highly qualified athletes at the age of $18.7 \pm 0.6$ years participated in the study. The following methods were used to investigate homeostasis indices: induced biochemiluminescence, determination of primary and end lipid peroxidation product content according to a modified Volchegorsky method, enzymatic colorimetric method of measuring the concentration of creatinine, lactate, glucose and free fatty acids, enzymatic kinetic method of determining the quantitative activity of creatine kinase and lactate dehydrogenase in the oral fluid.

Results. Anaerobic interval exercise is estimated to initiate increase of lactate dehydrogenase activity and lactate concentration, reduction of all parameters of chemiluminescence reaction curve, and elevation of the content of trien conjugates and Schiff bases in the oral fluid of highly qualified athletes.

Conclusion. The study of free radical oxidation indices as well as the content of primary and end products of lipid peroxidation is an available, highly informative method of examining the functional state, adaptive mechanisms, and spare capacities of athletes at all stages of training and competitive processes.

Key words: creatine kinase; lactate dehydrogenase; creatinine; lactate; glucose; free fatty acids; prooxidant-antioxidant homeostasis; oral fluid; physical exercise.

The search for new effective ways and means of operative diagnosis of the athlete functional state during physical exercises is one of the priority directions of the scientific investigations in the sports medicine. A biochemical screening is of a dominant significance in the current situation in the general complex of medicobiological investigations and instrumental control of the physical fitness level. The analysis of the biochemical homeostasis indices allows early diagnosis of the signs of physical overstrain, detection of microdamage in tissues, functional and structural shifts of adaptive processes under the influence of physical loads, and considering all these indices, the adjustment of the multilevel system of athlete training.
As a rule, blood, expired air, urine, more rarely sweat, and oral fluid are the objects of biochemical investigations. However, blood collection during a training process implies the presence of qualified personnel due to a strict necessity to comply with all stipulated protective measures, which, in case of permanent biochemical control in the process of sports training, is rather difficult to realize. Besides, blood collection results sometimes in instability of the psychological state of the examined sportsmen falsifying the tested parameters. Of special significance in performing these procedures is the fact of toughening the requirements for anti-doping control. Thus, any forms of intravascular or other manipulations with blood

For contacts: Klavdia N. Kontorshchikova, e-mail: kontkn@mail.ru 
or its components by physical or chemical methods were referred by WADA to the Prohibited List [1]. The existing situation determines the necessity of searching for other noninvasive diagnostic methods with a high degree of availability, specificity and sensitivity.

Recently, experts and scientists consider with increasing frequency oral fluid as an informative biological medium of the organism for conducting noninvasive biochemical screening. The oral fluid is known to provide interconnection of the body with external and internal environment [2]. Its composition includes organic and inorganic components from salivary glands, blood serum, and oral tissues [3]. All this create good opportunities for exploration of biochemical metabolism indices in the oral fluid during screening examinations of athletes.

Alterations of mineral balance, spectrum of steroid hormones, content of immune system components, activity of some enzymes, concentration of the most important metabolism products, fluctuations of acid-base balance are described in detail in the scientific literature [4-8]. However, we failed to find any works devoted to the investigations of free radical oxidation processes as well as to the study of the content of primary and end products of lipid peroxidation in the oral fluid of highly qualified athletes as diagnostic markers of the oxidative stress condition and negative consequences of its alteration on the organism during physical exercises of various types. Nevertheless, knowledge of these indices plays an important role in the evaluation of the state of the athletes subjected to a severe stress.

The aim of the investigation was to study the efficiency of determining the indices of free radical and peroxide processes in the oral fluid in highly qualified athletes under anaerobic interval exercise for the assessment of their functional state.

Materials and Methods. 23 representatives of the cyclic kinds of sports (track and field, swimming) bearing the title of Master of Sports of Russia or the category of Candidate Master of Sports took part in the investigation. An average age of the athletes was $18.7 \pm 0.6$ years. In compliance with the principles of the Declaration of Helsinki of the World Medical Association, all tested sportsmen have been preinformed about the aims and methods of conducting the study and gave voluntary consent to participate in the experiment.

Samples of the oral fluid were collected by spitting into $2 \mathrm{ml}$ plastic microcentrifuge tube of Eppendorf type without additional stimulation. Sportsmen were tested before and after the performance of the control test which consisted of the series of $3 \times 100 \mathrm{~m}$ distances by a flat race with an active $45 \mathrm{~s}$ rest between them for the track and field athletes, and $4 \times 50 \mathrm{~m}$ by the main swimming style with an active rest between the distances also for $45 \mathrm{~s}$ for the swimmers. During the control test the collected samples of the oral fluid were kept in the portable freezing chamber (Ezetil, Germany) at $-18^{\circ}$ and transported thereafter to the laboratory for biochemical investigations.
The potential intensity of the free radical process and the level of its compensatory mechanisms in the oral fluid were measured using a BHL-07 programmethodical complex of biochemiluminescence analysis (Medozons, Nizhny Novgorod, Russia) by means of induced biochemiluminescence [9]. The content of primary products of lipid peroxidation (dien conjugates (DC) and trien conjugates (TC)), and end products (Schiff bases (SB)), in the oral fluid were determined using the SF-2000 spectrophotometer (OKB Spectr, Saint Petersburg, Russia) according to a modified Volchegorsky technique [10]. Concentration of creatinine, lactate, glucose, and free fatty acids in the oral fluid was measured using Vital reagent kits (Vital Development Corporation, Russia) and NEFA FS DiaSys kits (DisSys, Germany) on the biochemical Stat Fax 1904 Plus analyser (Awareness Technology, USA) by means of enzymatic colorimetric method. Total activity of creatine kinase and lactate dehydrogenase was identified using CK-NAC DiaS and LDH DiaS DGKC reagent kits (DiaSys, Germany), respectively, on the biochemical Clima MC-15 analyser (RAL, Spain) by the enzymatic kinetic method in the range of $1-1,100 \mathrm{IU} / \mathrm{L}$ for creatine kinase, and the optimized kinetic UV-method in the range of $5-1,200 \mathrm{IU} / \mathrm{L}$ for lactate dehydrogenase.

Statistical analysis of the obtained data was performed using Microsoft Excel 2013 and Statistica 13.0 applied programs. The results were presented as arithmetic mean and standard error of mean $(\mathrm{M} \pm \mathrm{m})$. The test on compliance of the distribution with the normal law was performed by Shapiro-Wilk test. When the distribution of the obtained data was not normal by all the tested parameters, the statistically significant differences were further analyzed using the Wilcoxon test.

Results and Discussion. In compliance with the developed investigation program aimed at identifying the dominant mechanism of energy production during the presented control test, dynamics of the biological activity alteration of the basic enzymes and substrates of creatinine phosphokinase, and lactacidic mechanisms of ATP resynthesis in the oral fluid has been studied. Thus, the activity of lactate dehydrogenase, catalyzing interconversion of pyruvic and lactic acids as one of the most important reactions of anaerobic glycolysis, in response to the presented physical load increased statistically significantly by $41.74 \%$ (Table 1 ).

It is known that during a long intensive muscular activity energy consumption of the body is compensated mainly by the glycolytic mechanism of ATP resynthesis, whose characteristic feature in case of oxygen deficiency is the growth of lactate dehydrogenase activity with the respective elevation of the lactic acid concentration in the tissues [11]. Upon the accomplishment of the control test, the lactate content in the oral fluid of the examined athletes statistically increased by $31.25 \%$ (Table 2 ).

Lactate, influencing $\mathrm{Na}^{+} / \mathrm{H}^{+}$and $\mathrm{Na}^{+} / \mathrm{Ca}^{2+}$ exchange in the cell, stimulates the reduction of intracellular and extracellular $\mathrm{pH}$, which is accompanied by the 
Table 1

Activity of creatine kinase and lactate dehydrogenase in the oral fluid of the highly qualified athletes $(M \pm m)$

\begin{tabular}{lcc}
\hline \multicolumn{1}{c}{ Parameters } & $\begin{array}{c}\text { Before physical } \\
\text { exercise }\end{array}$ & $\begin{array}{c}\text { After physical } \\
\text { exercise }\end{array}$ \\
\hline Creatine kinase (relative units) & $71.08 \pm 5.23$ & $78.23 \pm 3.94$ \\
\hline $\begin{array}{l}\text { Lactate dehydrogenase } \\
\text { (relative units) }\end{array}$ & $390.29 \pm 23.64$ & $553.19 \pm 25.73^{*}$ \\
\hline
\end{tabular}

* Statistically significant difference of values before and after exercise, $p \leqslant 0.05$.

Table 2

Concentration of creatinine and lactate in the oral fluid of the highly qualified athletes (M $\pm m$ )

\begin{tabular}{lcc}
\hline \multicolumn{1}{c}{ Parameters } & $\begin{array}{c}\text { Before physical } \\
\text { exercise }\end{array}$ & $\begin{array}{c}\text { After physical } \\
\text { exercise }\end{array}$ \\
\hline Creatinine $(\mu \mathrm{mol} / \mathrm{L})$ & $16.45 \pm 2.47$ & $14.01 \pm 2.06$ \\
\hline Lactate $(\mathrm{mmol} / \mathrm{L})$ & $0.16 \pm 0.01$ & $0.21 \pm 0.02^{*}$ \\
\hline
\end{tabular}

* Statistically significant difference of values before and after exercise, $p \leqslant 0.05$.

Table 3

Content of glucose and free fatty acids in the oral fluid of the highly qualified athletes $(\mathrm{M} \pm \mathrm{m})$

\begin{tabular}{|lcc|}
\hline \multicolumn{1}{|c|}{ Parameters } & $\begin{array}{c}\text { Before physical } \\
\text { exercise }\end{array}$ & $\begin{array}{c}\text { After physical } \\
\text { exercise }\end{array}$ \\
\hline Glucose $(\mathrm{mmol} / \mathrm{L})$ & $0.42 \pm 0.02$ & $0.41 \pm 0.02$ \\
\hline Fatty acids $(\mathrm{mmol} / \mathrm{L})$ & $1.10 \pm 0.01$ & $1.20 \pm 0.01$ \\
\hline
\end{tabular}

impairment in functioning of many enzymatic systems including decrease of tissue respiration intensity, reduction of ATP and creatine phosphate content in the cells as well as a less active mobilization of neutral lipids from the fat depot by lipase inhibition. Absence of substantial dynamic changes in creatine kinase activity, concentration of creatinine, glucose, and fatty acids in the oral fluid of the athletes before and after the control test was most likely caused by the development of lactatemia (Table 3).

Investigation of the effect of anaerobic interval physical exercise on the state of the "lipid peroxideantioxidant protection" system in the oral fluid showed statistically significant reduction of all parameters of the chemiluminescent reaction curve compared to the data obtained at rest (Table 4).

Thus, S and Imax indices of the biochemiluminogram reduced statistically significantly by 22.29 and $14.73 \%$, respectively. But at the same time, despite the lower potential capability to free radical oxidation, the content of $T C$ and $S B$ in the oral fluid in the post-exercise condition was statistically significantly higher by 40.01 and $89.23 \%$ (Table 5).

The results obtained convincingly show intensification of the oxidative stress development during the performance of the presented physical activity, which is accompanied by a low degree of reactivity of the links of the antioxidant protection system. After the fulfillment of the control test, the index characterizing the direction of chain reactions of free radical lipid oxidation significantly increased by $49.94 \%$ towards the substantial prevalence of $\mathrm{SB}$ in the sportsmen oral fluid. Evidently, hypoxic state caused by the inadequacy between the oxygen demand and its current consumption during the accomplishment of the control test, initiated via the stimulation of sympatico-adrenal system an intensive formation of reaction-active oxygen forms with the following cascade growth of free radical and peroxide processes in the tissues. According to the literature data [12], pathological consequences for metabolic conditions in the organism, including suppression of glycolysis and oxidative phosphorylation activity, inhibition of the protein and nucleic acid synthesis, disturbance of various enzymatic processes, occur first of all in case of inability of the antioxidant self-system to maintain prooxidantantioxidant balance within the limits of physiological norm, which eventually results in the excessive accumulation of toxic products of lipoperoxidation and damage to the membrane structures: from changes in

Table 4

Parameters of oral fluid biochemiluminogram of the highly qualified athletes ( $\pm m$ )

\begin{tabular}{lcc}
\hline \multicolumn{1}{c}{$\begin{array}{c}\text { Index } \\
\text { of chemiluminescence }\end{array}$} & $\begin{array}{c}\text { Before physical } \\
\text { exercise }\end{array}$ & $\begin{array}{c}\text { After physical } \\
\text { exercise }\end{array}$ \\
$\mathrm{S}(\mathrm{mV} \cdot \mathrm{s})$ & $1,286.61 \pm 14.34$ & $999.79 \pm 13.12^{*}$ \\
$\mathrm{Imax}(\mathrm{mV})$ & $218.25 \pm 4.65$ & $186.11 \pm 3.94^{*}$ \\
$\mathrm{tga}_{2}$ & $78.34 \pm 1.44$ & $73.02 \pm 1.75^{*}$ \\
$\mathrm{~S} / \mathrm{Imax}$ (relative units) & $6.22 \pm 0.07$ & $5.69 \pm 0.04^{*}$ \\
\hline
\end{tabular}

* Statistically significant difference of values before and after exercise, $p \leqslant 0.05$.

Table 5

Content of lipid peroxidation products in the oral fluid of the highly qualified athletes $(\mathrm{M} \pm \mathrm{m})$

\begin{tabular}{lcc}
\hline \multicolumn{1}{c}{ Parameters } & $\begin{array}{c}\text { Before physical } \\
\text { exercise }\end{array}$ & $\begin{array}{c}\text { After physical } \\
\text { exercise }\end{array}$ \\
\hline DC (relative units) & $0.29 \pm 0.01$ & $0.31 \pm 0.02$ \\
\hline TC (relative units) & $0.35 \pm 0.03$ & $0.49 \pm 0.04^{*}$ \\
\hline SB (relative units) & $99.94 \pm 9.41$ & $189.12 \pm 7.69^{*}$ \\
\hline SB/(DC+TC) (relative units) & $158.65 \pm 9.22$ & $237.88 \pm 8.84^{*}$ \\
\hline
\end{tabular}

* Statistically significant difference of values before and after exercise, $p \leqslant 0.05$. 
permeability and barrier function to the cell lysis and apoptosis. Impairment of the prooxidant-antioxidant balance towards the substantial predominance of the end products of macromolecule oxidative modification is one of the factors limiting physical fitness and augmenting the risk of developing premorbid and pathological states in athletes.

Conclusion. The study of free radical oxidation indices as well as the content of primary and end products of lipid peroxidation is an available, highly informative method of examining the functional state, adaptive mechanisms, and spare capacities of athletes at all stages of training and competitive processes.

Study Funding. The work was not supported by any sources.

Conflicts of Interest. The authors have no conflicts of interest to disclose.

\section{References}

1. World Anti-Doping Agency. The World Anti-Doping Code. International Standard. Prohibited List 2017. URL: https://www. wada-ama.org/sites/default/files/resources/files/2016-09-29_-_ wada_prohibited_list_2017_eng_final.pdf.

2. Komarova L.G., Alekseeva O.P. Salivalogiya [Salivalogy]. Nizhny Novgorod: NizhGMA; 2006; 180 p.

3. Gil'miyarova F.N., Radomskaya V.M., Ryskina E.A., et al. Analiticheskie podkhody $k$ izucheniyu pokazateley metabolizma $v$ rotovoy zhidkosti [Analytical approaches to the study of metabolism indices in the oral fluid]. Moscow: Izvestiya; 2006; 312 p.

4. Guilhem G., Hanon C., Gendreau N., Bonneau D., Guével A., Chennaoui M. Salivary hormones response to preparation and pre-competitive training of world-class level athletes. Front Physiol 2015; 6: 333, https://doi.org/10.3389/ fphys.2015.00333.
5. Moreira A., Bacurau R.F., Napimoga M.H., Arruda A.F., Freitas C.G., Drago G., Aoki M.S. Salivary IL-21 and IgA responses to a competitive match in elite basketball players. Biol Sport 2013; 30(4): 243-247, https://doi. org/10.5604/20831862.1077548.

6. Tékus E., Kaj M., Szabó E., Szénási N.L., Kerepesi I., Figler M., Gábriel R., Wilhelm M. Comparison of blood and saliva lactate level after maximum intensity exercise. Acta Biol Hung 2012; 63(Suppl 1): 89-98, https://doi.org/10.1556/ abiol.63.2012.suppl.1.9.

7. Damirchi A., Saati Zareei A., Sariri R. Salivary antioxidants of male athletes after aerobic exercise and garlic supplementation on: a randomized, double blind, placebocontrolled study. J Oral Biol Craniofac Res 2015; 5(3): 146152, https://doi.org/10.1016/j.jobcr.2015.08.001.

8. Sant'Anna M., Casimiro-Lopes G., Boaventura G., Marques S.T., Sorenson M.M., Simão R., Pinto V.S. Anaerobic exercise affects the saliva antioxidant/oxidant balance in high-performance pentathlon athletes. Human Movement 2016; 17(1): 50-55, https://doi.org/10.1515/humo2016-0003.

9. Kuz'mina E.I., Nelyubin A.S., Shchennikova M.K. Primenenie indutsirovannoy khemilyuminestsentsii dlya otsenki svobodnoradikal'nykh reaktsiy $\mathrm{v}$ biologicheskikh substratakh. $\mathrm{V}$ kn.: Biokhimiya i biofizika mikroorganizmov [The use of induced chemiluminescence to assess free radical reactions in biotic substrates. In: Biochemistry and biophysics of microorganisms]. Gorky; 1983; p. 179-183.

10. Volchegorsky I.A., Nalimov A.G., Yarovinskiy B.G., Lifshits R.I. Comparison of various approaches to determination of lipid peroxidation products in heptaneisopropanol extracts of blood. Voprosy meditsinskoy khimii 1989; 35(1): 127-131.

11. Mikhaylov S.S. Sportivnaya biokhimiya [Biochemistry for sport]. Moscow: Sovetskiy sport; 2006; 260 p.

12. Gunina L.M. Oxidative stress and adaptation: metabolic aspects of physical activity impact. Nauka $v$ olimpiyskom sporte 2013; 4: 19-25. 